\title{
Editorial: Whence and whereto?
}

\section{Joaquin Marti PhD}

Director, Principia, Madrid, Spain

The birth of a journal with the title Environmental Geotechnics is a momentous event and calls for a reflection. I offer here my own.

Let me start by highlighting the excellent title of the journal. Paraphrasing Baltasar Gracián, "a good title, if brief, is twice as good". Environmental Geotechnics condenses the subject matter in just two words, deep and meaningful, ground engineering and the concern for the environment, and incorporates their mutual interactions.

When I started my career in the mid-1970s, immediately after a geotechnical $\mathrm{PhD}$, I joined a large international partnership, where practically all the professionals were fully dedicated to geotechnical engineering. About a decade later, more than half of their activities had a primarily environmental character and many of their engineers had to retrain or extend their capabilities into the new expanding field. A growing social awareness had started to affect governments' regulations and clients' requirements, and consultants were duly responding to those needs.

The change was also reflected in the technical literature. Simply as an example in our field, after 1995 the ASCE Journal of Geotechnical Engineering became the Journal of Geotechnical and Geoenvironmental Engineering, as environmental issues were motivating a progressively greater proportion of geotechnical endeavours. And this was not restricted to soil and rock science; oceanography, atmospheric and other sciences underwent a similar drift. Furthermore, although not exactly synchronous everywhere, the trend has been universally experienced.

Looking with a historical perspective, mankind is well used to pendular movements in the establishment of priorities. Until perhaps half a century ago, the environment was being used as an essentially bottomless dump, suitable for hosting nuclear tests, dangerous tailings and all sorts of industrial and urban waste, with only minor supervision, if any. Today, environmental impact assessments are the element that makes or breaks huge projects, with potentially enormous economic and social impacts. Furthermore, environmental issues are often used as projectiles that opposing interest groups, with variable justification, throw at each other when trying to advance their cause. Think of activities like fracking, nuclear plants or wind turbines; or projects like Keystone XL, Sakhalin gas or Romanian gold.

As scientists and engineers, those parties in conflict are often our clients. Our duties are certainly to our clients, at least while higher ethical issues are not at stake. Fortunately, our assignments are generally restricted to narrow technical issues, but that may not always be the case.

Having recalled the evolution over the last half a century, a sobering thought may be to ponder how our grandchildren will view all these issues some 50 years from now, perhaps while basking on a warmer planet with raised sea levels. Will the environmental concerns have grown, decreased or remained as they are now? Will the pendulum go back to some intermediate position, as if a passing fad, under the pressures of other socially perceived priorities? Or will it continue advancing in the same direction, impelled by a growing sense of urgency in matters environmental? Rather than trying to answer, I will quote Niels Bohr: "Prediction is very difficult, especially about the future".

\section{WHAT DO YOU THINK?}

To discuss this paper, please submit up to 500 words to the editor at journals@ice.org.uk. Your contribution will be forwarded to the author(s) for a reply and, if considered appropriate by the editorial panel, will be published as a discussion in a future issue of the journal. 